\title{
Coronary Lumen at Six-Month Follow-Up of a New Radiopaque Cordis Tantalum Stent Using Quantitative Angiography and Intracoronary Ultrasound
}

\author{
Yukio Ozaki, MD, PhD, David Keane, MB, MRCPI, PhD, Masakiyo Nobuyoshi, MD, PhD, \\ Naoya Hamasaki, MD, Jeffrey J. Popma, MD, and Patrick W. Serruys, MD, PhD
}

To determine the reliability of geometric ledge-detection) quantitative coronary angiographic analysis (QCA) of restenosis within a new Cordis tantalum stent, QCA and intracoronary ultrasound (ICUS) measurements were compared in both an experimental restenosis model and in the clinical follow-up of patients. In the experimental series, Plexiglas ${ }^{\mathrm{TM}}$ phantom vessels with concentric stenosis channels ranging from 0.75 to $3.0 \mathrm{~mm}$ in diameter and with a reference diameter of $3.0 \mathrm{~mm}$ were imaged both before and after their insertion in tantalum stents. In the clinical series, the agreement of QCA and ICUS measurements were studied in 23 patients who had undergone coronary implantation of the new tantalum stent and in 23 patients who had undergone balloon angioplasty 6 months previously. The reliability of QCA declined in the presence of the radiopaque stent (accuracy of QCA decreased from -0.07 to $-0.12 \mathrm{~mm}$ ), whereas the reliability of lumen measurements by ICUS was independent of the presence of the radiopaque stent $(-0.12$ and $-0.13 \mathrm{~mm})$. Without the stent, the average minimal luminal diameter (MLD) obtained by QCA of the $1.00 \mathrm{~mm}$ Plexiglas vessel was $1.00 \pm 0.01 \mathrm{~mm}$, and the $3.00 \mathrm{~mm}$ reference vessel diameter was $2.81 \pm 0.05 \mathrm{~mm}$, providing a $64 \pm 1 \%$ diameter stenosis. After introduction of the stent, the average MLD and reference vessel diameter were 0.99 \pm 0.06 and $3.36 \pm 0.17 \mathrm{~mm}$, respectively, providing a diameter stenosis of $71 \pm 2 \%$. ICUS measurements $(2.77$ $\mathrm{mm}$ ) of the reference vessel diameter $(3.00 \mathrm{~mm})$ were unaffected by the presence of the stent. Agreement of ICUS and QCA measurements (ICUS - QCA) was poorer in patients who had undergone balloon angioplasty $(0.68 \pm 0.42 \mathrm{~mm})$ than in patients who had stent implantation $(-0.05 \pm 0.42 \mathrm{~mm})$. In the 6-month follow-up of patients who had undergone implantation of a highly radiopaque Cordis tantalum stent, assessment of restenosis was reliably quantified by QCA with the use of the MLD rather than the percent diameter stenosis. Although ICUS measurements are unaffected by the radiopaque stent, the mechanical problem of ICUS catheter wedging in stenoses of $<1.00 \mathrm{~mm}$ and the substantial cost of ICUS catheters will restrict the widespread application of ICUS for the assessment of intrastent restenosis.

(Am J Cardiol 1995;76:1135-1143)
17 hereas most of the available coronary stents are of low or moderate radiopacity, ${ }^{1-4}$ a new helical coil stent composed of crenulated 0.005 -inch tantalum wire (Cordis, Miami, Florida) is highly radiopaque. Although during the interventional procedure itself, the strong radiopacity of tantalum stents facilitates the precise positioning of the stent in the target lesion and the subsequent placement of additional noncompliant balloons for high-pressure intrastent inflations, the radiopaque stent struts may interfere with the quantitative assessment of restenosis within the stent at angiographic follow-up. ${ }^{5,6}$ To evaluate the potential application and reliability of computer-based quantitative coronary an-

From the Catheterization Laboratory, Thoraxcenter, Erasmus University, Rotterdam, The Netherlands; Catheterization Laboratory, Department of Cardiology, Kokura Memorial I lospital, Kitakyushu, Japan; and the Department of Internal Medicine (Cardiology Division), Washington Hospital Center, Washington D.C. Dr. Ozaki is a recipient of a grant from Takeda Medical Research (Taisha lio) Foundation, Osaka, Japan. Dr. Keane is a recipient of a travel grant from the Peel Medical Research Trust, London, United Kingdom. Manuscript received May 16, 1995; revised manuscript received and accepted August 24, 1995.

Address for reprints: Patrick W. Serruys, MD, PhD, Thoraxcenter, Erasmus University, P.O. Box 1738, 3000 DR Rotterdam, The Netherlands. giographic analysis (QCA) of restenosis within the new radiopaque stent, we compared automated QCA and intracoronary ultrasound (ICUS) measurements of the vessel lumen with and without the radiopaque stent in both an in vitro Plexiglas (ICI, Rotterdam, The Netherlands) restenosis model as well as in a 6-month follow-up of patients who had undergone implantation of the new tantalum stent and patients who had undergone balloon angioplasty 6 months previously.

\section{METHODS}

Experimental series: EXPERIMENTAL IMAGE ACQUISITION OF PLEXIGLAS RESTENOSIS MODEL WITH AND WITHOIT STFNT: The stenosis phantoms were produced at the workshop of Erasmus University, Rotterdam, The Netherlands. For the in vitro assessment of restenosis measurements within a new radiopaque stent, phantom vessels were filmed before and after their insertion in new balloon-expanded tantalum stents of $3.5 \mathrm{~mm}$ nominal diameter (see Figure 1). Phantom vessels were composed of radiolucent Plexiglas cylinders (35 mm in length, 3.6 $\mathrm{mm}$ in outer diameter) with precision-drilled concentric circular lumens of $0.75,1.0,1.25,1.5,2.0,2.5$, and 3.0 $\mathrm{mm}$ in diameter. ${ }^{7-9}$ The length of each phantom stenosis channel was $5 \mathrm{~mm}$ and the adjacent "normal refer- 
ence" channel length of the proximal and distal segments was $15 \mathrm{~mm}$. The Plexiglas channel, including the artificial stenosis, was filled with contrast medium (Iopamidol $370^{\mathrm{rM}} ; 370 \mathrm{mg}$ iodine/ml [Bracco, Milan, Italy]). Cinefilm acquisition was performed with additional Plexiglas blocks (50 $\mathrm{mm}$ anteriorly and $50 \mathrm{~mm}$ posteriorly). These Plexiglas blocks provide a more appropriate $\mathrm{kV}$ level and a scatter medium that more closely approximates the radiologic scatter of the human thorax during angiography. Angiograms were recorded using a 5-inch field-ofimage intensifier, with separate recordings using 2 different focal spots $(0.4$ and $0.7 \mathrm{~mm})$. All phantoms were imaged at the radiographic isocenter of the x-ray gantry ${ }^{10}$ and acquired on $35 \mathrm{~mm}$ cinefilm (Kodak CFE type 2711, Paris, France). For each of the 7 phantom vessels, 10 cineframes were selected both before and after their insertion in the new tantalum stents, providing a total of 140 cineframes for quantitative analysis.

Clinical series: CORONARY BALLOON ANGIOPLASTY: Balloon angioplasty was performed in 23 lesions of 23 patients at the Thoraxcenter, Erasmus University, Rotterdam, The Netherlands. The size of the balloon was selected to match the reference vessel diameter obtained from on-line quantitative angingraphic analysis after intracoronary administration of isosorbide dinitrate. ${ }^{11,12}$ Of the 23 lesions treated, a $2.5 \mathrm{~mm}$ diameter balloon was used in 6 lesions, a $3.0 \mathrm{~mm}$ in 10 lesions, a $3.5 \mathrm{~mm}$ in 6 lesions, and a $4.0 \mathrm{~mm}$ balloon in 1 lesion. Of the 23 lesions, 11 were in the left anterior descending coronary artery, 5 in the left circumflex coronary artery, and 7 in the right coronary artery. The follow-up angiogram and ICUS examination were performed at $6 \pm 2$ months after balloon angioplasty.

CORONARY STENT IMPLANTATION: After predilatation, a new radiopaque coronary Cordis stent was implanted in 23 lesions of 23 patients at Kokura Memorial Hospital, Kitakyushu, Japan. Twenty-one stents were implanted in 21 lesions of 21 patients and 4 stents were deployed in 2 lesions of 2 patients ( 2 stents in each lesion). Of the 25 stents used in 23 lesions, 14 stents were $3.0 \mathrm{~mm}$ and 11 were $3.5 \mathrm{~mm}$ in diameter. Of the 23 lesions, 11 were in the left anterior descending coronary artery, 5 in the left circumflex coronary artery, and 7 in the right coronary artery. Follow-up angiographic and ICUS examinations were performed at $6 \pm 1$ months after stent implantation. The number and location of lesions were identical in the balloon angioplasty and stent implantation groups.

CLINICAL ANGIOGRAPHIC IMAGE ACQUISITION AT 6MONTH FOLLOW-UP: Six-month follow-up coronary angiography was performed after the administration of intracoronary isosorbide dinitrate ${ }^{11,12}$ before manual injection of contrast medium (Iopamidol 370; $370 \mathrm{mg}$ iodine $/ \mathrm{ml}$ ) at $37^{\circ} \mathrm{C}$. The 5-inch field-of-image intensifier was selected and the radiographic settings were kept constant $(\mathrm{kV}$, $\mathrm{mA}, \mathrm{x}$-ray pulse width) in each projection. All clinical images were acquired on $35 \mathrm{~mm}$ cinefilm at a frame rate of 25 images/s. An average of 2.6 cineframes/patient was selected for quantitative angiographic analysis: Minimal luminal diameter (MLD), reference vessel diameter, and luminal dimension at the proximal and distal extremities of the radiopaque stent were measured.

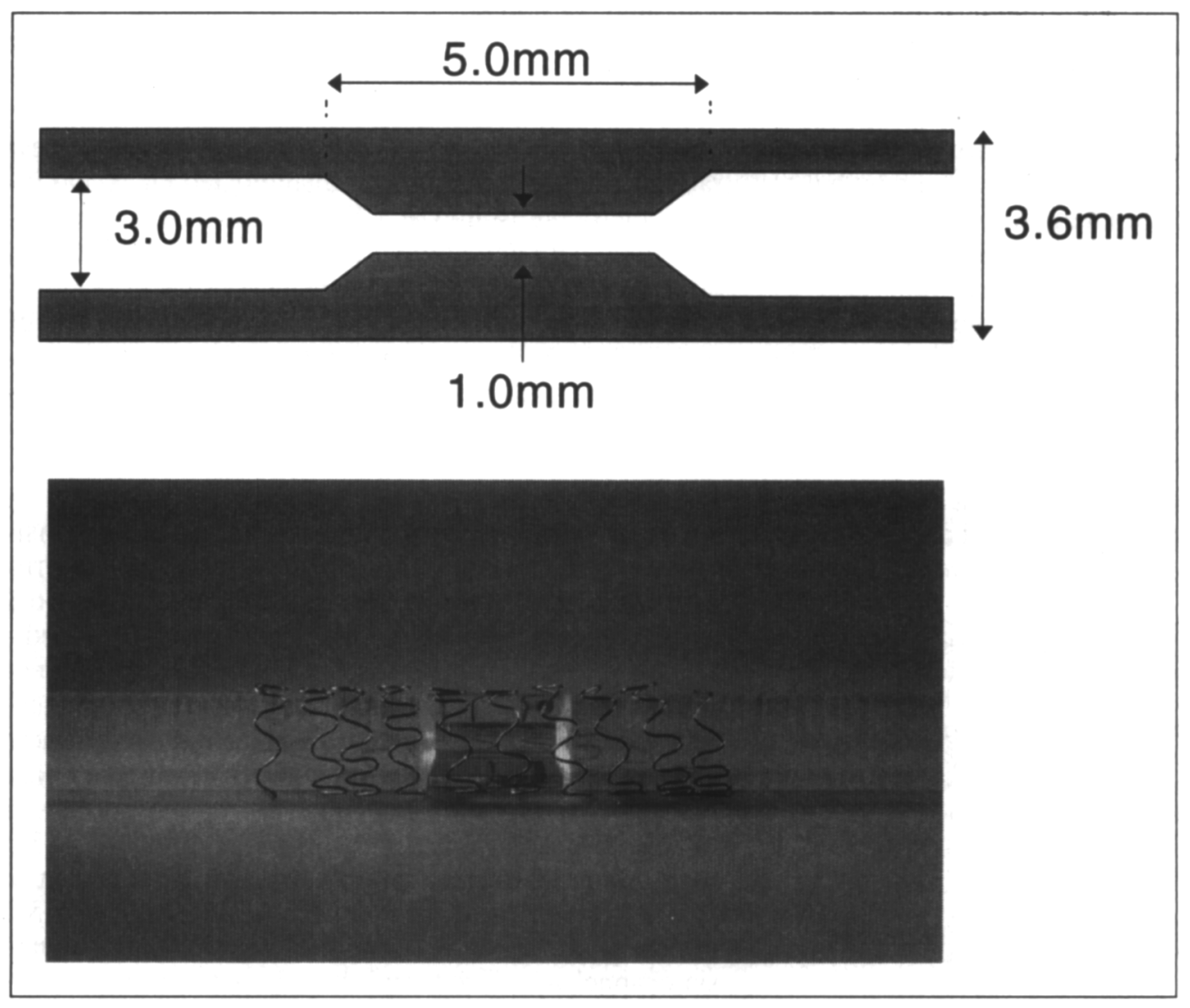

FIGURE 1. The phantom Plexiglas vessel served as an in vitro model for intrastent restenosis by insertion of the model into the expanded stent. Quantitative angiographic measurements were obtained of the contrast-filled lumen without and subsequently with the Cordis stent. 
Quantitative angiographic analysis: Cinefilms from both the experimental and clinical series were quantitatively analyzed using a computer-based Cardiovascular Angiographic Analysis System (CAAS II; Pie Medical, Maastricht, The Netherlands). ${ }^{7-9,12-17}$ Before performance of the calibration and analyses of the stenoses, computerized correction for pincushion distortion was applied by the recording and subsequent off-line digitization of a centimeter grid placed in front of the image intensifier in each cardiac catheterization laboratory. For both the experimental and clinical angiograms, quantitative measurements were calibraled by the use of the recorded contrast-free catheter tip as a scaling device. ${ }^{18}$ The nontapering catheter tip was measured with a precision micrometer (no. 293-501, Mitutoyo, Tokyo, Japan; accuracy $0.001 \mathrm{~mm}$ ). In the experimental study, a sufficiently long segment of the Plexiglas cylinders, including the phantom stenosis with or without the stent, was selected for analysis. In the clinical study, frames without foreshortening or overlapping side branches were selected. ${ }^{19}$ Arterial dimensions of clinical frames were measured at specific distances from identifiable branch points in end-diastolic frames.

In the CAAS II system; the entire cineframe of size $18 \times 24 \mathrm{~mm}$ is digitized at a resolution of $1,329 \times 1,772$ pixels. In the CAAS system, the edge-detection algorithm is based on the first and second derivative functions applied to the digitized brightness profile along scanlines perpendicular to a model using minimal cost criteria. ${ }^{16}$ A computer-derived estimation of the original dimensions of the vessel at the site of the obstruction was used to determine the interpolated reference vessel diameter. If the automatically detected contour did not faithfully track the border of the lumen, the level of the light-emitting diode, which regulated the image brightness during digitization of the cineframe, was changed. Manual correction of the automatically detected contours was not performed in either the experimental phantom or the clinical studies. MLD and reference diameter were quantified in multiple averaged views.

Image acquisition of intracoronary ultrasound: After selective coronary angiography, a mechanical ICUS imaging catheter $(30 \mathrm{MHz}, 2.9 \mathrm{Fr}$, Cardiovascular Imaging Systems, Sunnyvale, California) was introduced over a 0.014 -inch guidewire. In the experimental series, a slow manual pullback was performed to assess the luminal dimension at the site of stenosis. In the clinical series, after the imaging catheter was passed into and beyond the lesion, a motorized pullback (Cardiovascular Imaging Systems) with a constant speed of $0.5 \mathrm{~mm} / \mathrm{s}$ was begun to obtain an initial assessment of the target lesion. A simultaneous fluoroscopic image of the position of the ICUS catheter tip was continuously displayed. Side branches and stent struts visible on both the ultrasound and angiographic images served as reference points to ensure that the coronary sites of ultrasound and quantitative angiographic analysis were identical. ICUS images were stored on super VHS videotape for subsequent analysis.

Quantitative assessment of intracoronary ultrasound: The luminal area was defined as the integrated area central to the intimal leading-edge echo. Images with min-
TABLE I Results of Measurements of the Minimal Luminal Diameter Within the Plexiglas Vessel With and Without Stents*

\begin{tabular}{llll|}
\hline Comparison & Accuracy & Precision & Correlation \\
\hline $\begin{array}{c}\text { QCA in stenosis without stent } \\
\text { versus phantom diameter }\end{array}$ & -0.07 & \pm 0.08 & 0.997 \\
$\begin{array}{c}Q C A \text { in stenosis with stent } \\
\text { versus phantom diameter }\end{array}$ & -0.12 & \pm 0.10 & 0.992 \\
$\begin{array}{c}\text { ICUS in stenosis without stent } \\
\text { versus phantom diameter }\end{array}$ & -0.12 & \pm 0.09 & 0.989 \\
$\begin{array}{c}\text { ICUS in stenosis with stent } \\
\text { versus phantom diameter }\end{array}$ & -0.13 & \pm 0.11 & 0.986 \\
\hline $\begin{array}{l}* p<0.001 . \\
\text { ICUS }=\text { intracoronary ultrasound; } Q C A=\text { quantitative coronary angio- } \\
\text { graphic analysis. }\end{array}$ & & & \\
\hline
\end{tabular}

imal cross-sectional area in the stent were selected from the pullback sequence by reviewing the position of the ICUS catheter on the angiographic image. Contrary to QCA, calculation of the reference vessel diameter by ICUS is based on a point measurement and is not interpolated. MLD and reference vessel diameter were derived from the minimal cross-sectional area $\left(\pi r^{2}\right)$. To

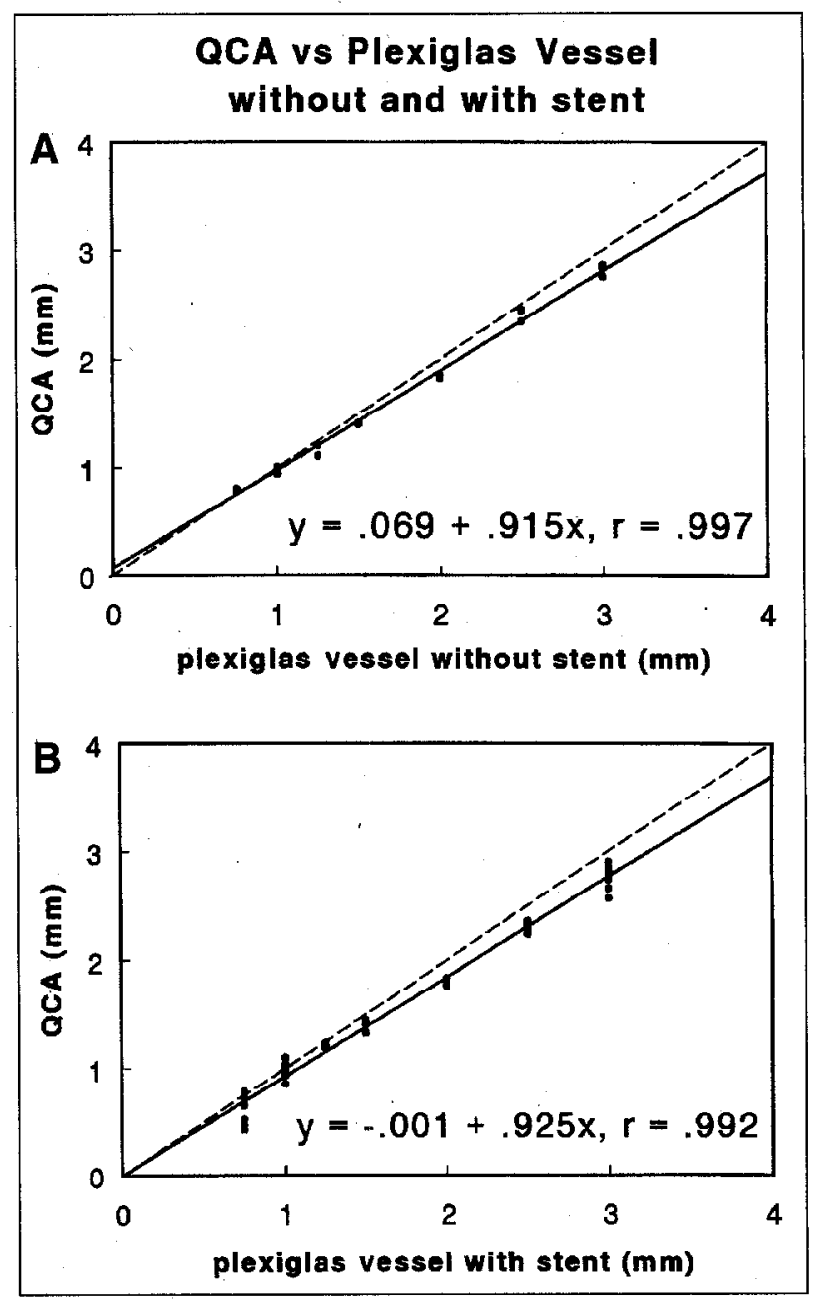

FIGURE 2. Quantitative coronary angiographic analysis (QCA) obtained from 70 cineframes of the Plexiglas restenosis model without (A) and subsequently with (B) insertion of the vessel in the new tantalum stent. The measurement values have been plotted against the true diameter of the contrast-filled lumen of the Plexiglas vessel (linear regression). 
determine the interobserver variability of ICUS measurements, 30 lesions were independently measured by 2 observers. The mean signed difference and correlation of the measurements of cross-sectional area were $0.02 \pm$ $0.37 \mathrm{~mm}^{2}$ and 0.97 , respectively.

Statistical analysis: In the experimental study, the mean of the signed differences between the true phantom diameters and the individual MLD values derived from measurements of QCA and ICUS was considered an index of accuracy, and the SD of the differences was considered an index of precision. In the clinical study, the mean \pm SD of the signed differences between measurements of MLD derived from QCA and from ICUS were used as an index of agreement between measurements. ${ }^{20}$

\section{RESULTS}

Experimental series: EXPERIMENTAL RESULTS FOR MINIMAL LUMINAL DIAMETER: Results of measurements of the MLD within the Plexiglas vessel with and without the stent are presented in Table $I$ and in Figures 2A and 2B (QCA) and 3A and 3B (ICUS). Before positioning the Plexiglas vessels in the stents, measurements of the phantom vessel lumen by QCA were more accurate than ICUS.

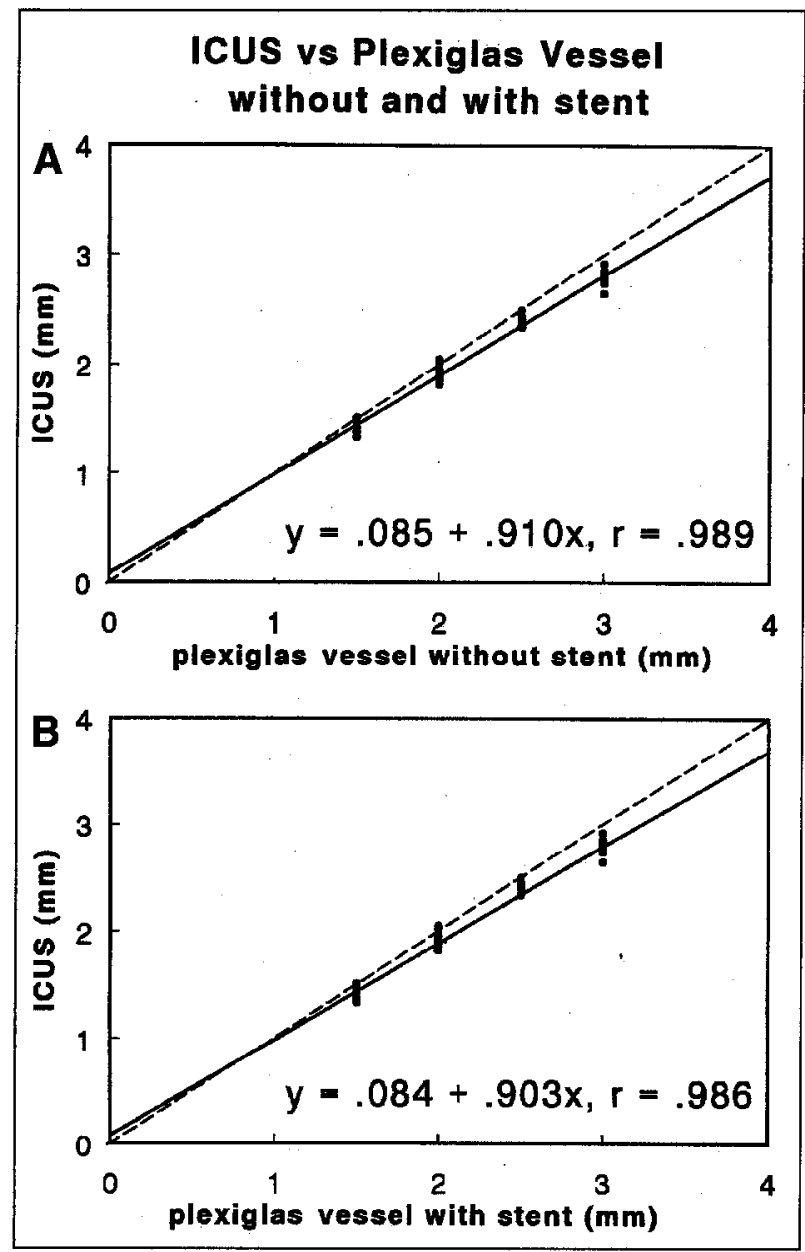

FIGURE 3. Intracoronary ultrasound (ICUS) measurements obtained from $\mathbf{4 0}$ frames of the Plexiglas restenosis model without (A) and subsequently with (B) insertion of the vessel in the new tantalum stent. The measurement values have been plotted against the true diameter of the contrast-filled lumen of the Plexiglas vessel (linear regression).
The reliability of QCA, however, declined in the presence of the radiopaque stent (accuracy of QCA decreased from -0.07 to $-0.12 \mathrm{~mm}$ ), whereas the reliability of lumen measurements by ICUS was independent of the presence of the radiopaque stent $(-0.12$ and $-0.13 \mathrm{~mm}$ before and after introduction of the stent, respectively).

EXPERIMENTAL RESULTS OF REFERENCE VESSEL DIAMETER AND PERCENT DIAMETER STENOSIS: Results of reference vessel measurements by QCA and ICUS are displayed in Figures 4A and 4B. Measurement by QCA of the reference vessel diameter was significantly larger within than without the stent $(\mathrm{p}<0.001)$ and the percent diameter stenosis was consequently significantly more severe with than without the stent $(\mathrm{p}<0.001)$. Without the stent, the average MLD obtained by QCA of the 1.00 $\mathrm{mm}$ Plexiglas vessel was $1.00 \pm 0.01 \mathrm{~mm}$, and the reference vessel diameter was $2.81 \pm 0.05 \mathrm{~mm}$, providing a $64 \pm 1 \%$ diameter stenosis. After introduction of the Plexiglas vessel in the stent, the average MLD was 0.99 $\pm 0.06 \mathrm{~mm}$, and the average reference vessel diameter was $3.44 \pm 0.10 \mathrm{~mm}$, providing a diameter stenosis of $71 \pm 2 \%$. An example of angiographic measurement of the MLD and reference vessel diameter of a Plexiglas

\section{Reference Diameter of Plexiglas. Vessel by QCA and by ICUS}
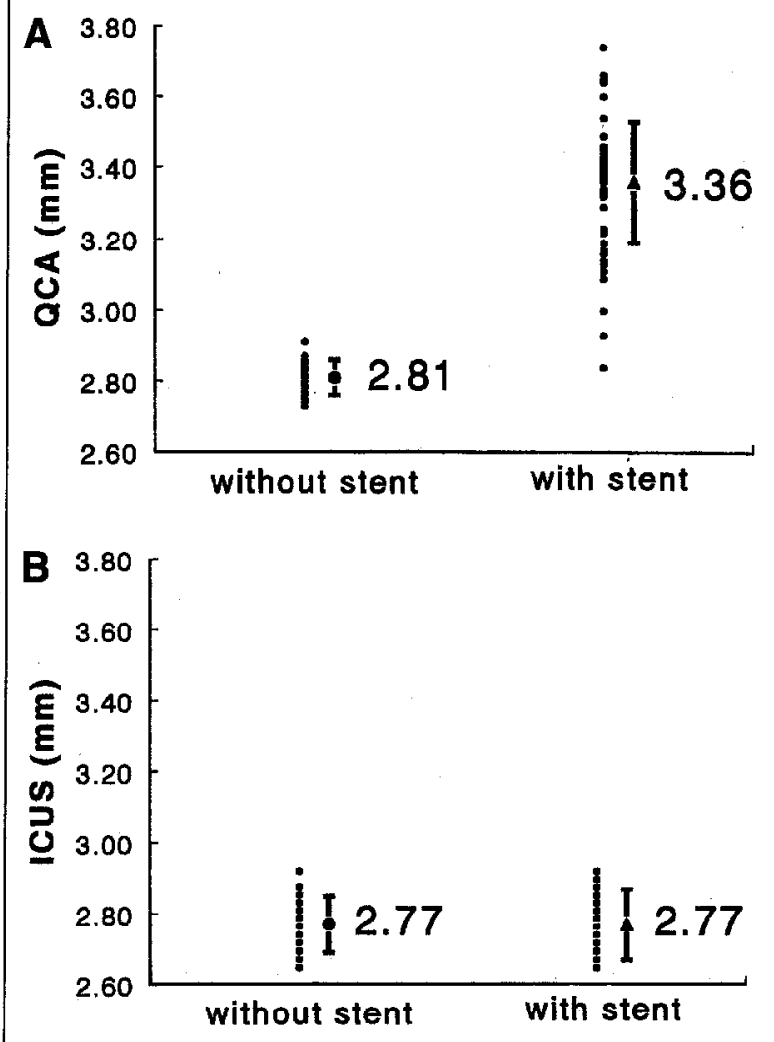

FIGURE 4. Comparison of reference diameter obtained from quantitative coronary angiographic analysis (QCA) (A) and by intracoronary ultrasound (ICUS) (B) without and with the new radiopaque stent. Although measurement obtained by quantitative coronary angiographic analysis of the reference vessel diameter within the stent was significantly larger than without the stent $(p<0.001)$, intracoronary ultrasound measurements were unaffected by the radiopaque stent $(p=N S)$. 
vessel with and without the new radiopaque stent can be seen in Figure 5. ICUS measurements $(2.77 \mathrm{~mm})$ of the reference vessel diameter $(3.00 \mathrm{~mm})$ were unaffected by the presence of the stent.

Clinical series: The results of measurements of MLD by ICUS are plotted against those by QCA for patients who had balloon angioplasty and those who had coronary stents in Figures $6 \mathrm{~A}$ and $6 \mathrm{~B}$, respectively. Of the 23 stented lesions, 3 showed signs of catheter wedging of the ICUS catheter, and in the remaining 20 lesions the minimal cross-sectional area and MLD were measured. Of the 23 balloon angioplasty lesions, 8 showed signs of catheter wedging. The agreement of ICUS and QCA measurements (ICUS - QCA) was poorer in patients who had undergone balloon angioplasty $(0.68 \pm 0.42$ $\mathrm{mm})$ than in patients who had stent implantations $(-0.05$ $\pm 0.42 \mathrm{~mm}$ ). Similarly, correlation of ICUS and QCA measurements was 0.40 in the balloon angioplasty population and 0.60 in the stented patients.

To ensure that the differences between QCA and ICUS measurements of the minimal lumen diameter were not related to analysis at different locations in the stented coronary segment by ICUS and QCA, measurements were also compared at the proximal and distal extremities of the stent, which were clearly identifiable during both QCA and ICUS analysis. The results of measurements of the luminal dimension at the proximal and distal extremity of each radiopaque stent (46 measurements) by ICUS are plotted against those by QCA in Figure 7. Agreement between the 2 sets of measurements at the extremity of the stent was $-0.06 \pm 0.42 \mathrm{~mm}$ (mean $\pm \mathrm{SD}$ of the signed differences), and was associated with a correlation coefficient of 0.63. An example of angiographic measurement of the MLD of a patient with a new radiopaque stent at 6-month follow-up can be seen in Figure 8.

\section{DISCUSSION}

The principal findings of our study are: (1) In the Plexiglas restenosis model, QCA provided more accurate measurements of MLD than ICUS. (2) After introduction of the Plexiglas vessel in the radiopaque stent, the accuracy of QCA declined, whereas the accuracy of ICUS measurements of both the MLD and the reference vessel diameter was unaffected by the radiopaque stent. (3) Measurements by QCA of the interpolated reference vessel diameter of the Plexiglas vessel were rendered inaccurate by the presence of the radiopaque stent and resulted in overestimation of the severity of the percent diameter stenosis. (4) In the 6-month follow-up of patients after coronary intervention, agreement of ICUS and QCA measurements was higher in patients who underwent stent implantation than in those who underwent balloon angioplasty alone.

Comparison between intravascular ultrasound and edge-detection quantitative coronary angiographic measurement: Previous studies examining the relation of ICUS and QCA measurements in normal coronary segments reported a favorable correlation between the 2 quantitative imaging modalities, ${ }^{21,22}$ whereas studies that included lesions after balloon angioplasty reported a poor correlation of the 2 measurement techniques. ${ }^{23-25}$ Complex morphologic changes caused by balloon angioplasty may result in a failure of agreement between the 2 measurement systems after balloon angioplasty, ${ }^{26}$ whereas the more smooth and circular lumen of a stented coronary segment may improve agreement of ICUS and QCA measurements.

Limitation of quantitative coronary angiographic analysis: During QCA of the MLD within a stented vessel segment, the automated edge-detection algorithm will trace the true diameter of the contrast-filled lumen at the point

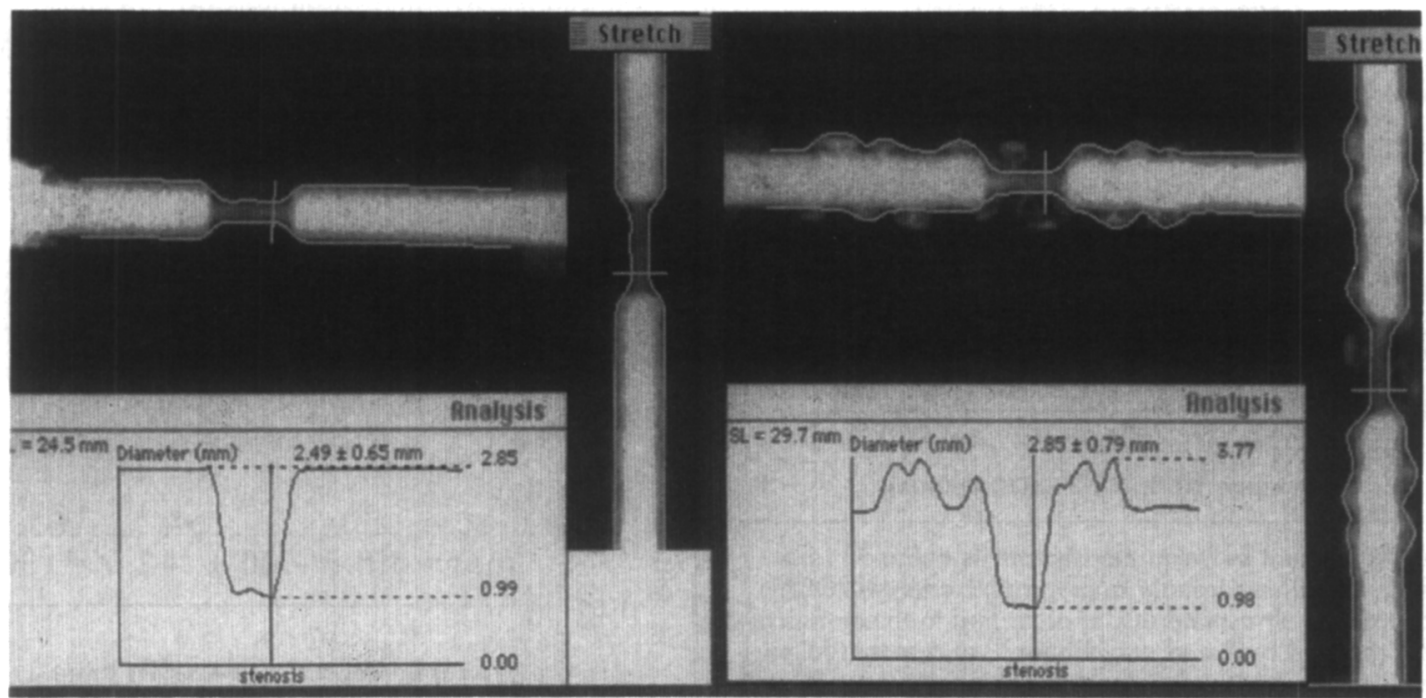

FIGURE 5. The contrast-filled lumen of the Plexiglas vessel is shown without the new Cordis tantalum stent (left panel) and after insertion of the vessel within the radiopaque stent (right panel). Automated quantitative angiographic analysis was found to faithfully track the contour of the stenotic segment in both the absence and subsequent presence of the stent. Automated quantitative angiographic analysis of the normal reference vessel diameter, however, was significantly affected by the presence of the radiopaque stent, with undulations and evident tracking out to include the contour of the stent struts rather than tracking the true edge of the contrast filled lumen. The maximal diameter was found to be $3.77 \mathrm{~mm}$ after introduction of the stent. Overestimation of the reference vessel diameter in the presence of the stent resulted in an exaggeration of the severity of the percent diameter stenosis. 
of most severe stenosis in between the radiopaque stent struts (i.e., in the interstrut intervals). QCA of the MLD will thus remain reliable for 2 reasons: First, at 6-month follow-up in the presence of significant intimal hyperplasia, the outer edge of the radiopaque stent struts will be deeply embedded in the vessel wall at an adequate distance from the border of the contrast-filled true lumen and will thus not interfere with the automated edgedetection process. Second, the measurement is based on a very limited segment of the coronary lumen (according to the degree of smoothing or minimal cost criteria), which is shorter in length than the gap between successive radiopaque stent struts. However, during measurement of the interpolated reference vessel diameter, QCA by automated edge detection may be unreliable for 2 reasons: First, beyond the subsegment of maximal restenosis, the outer contour of the radiopaque stent struts lies

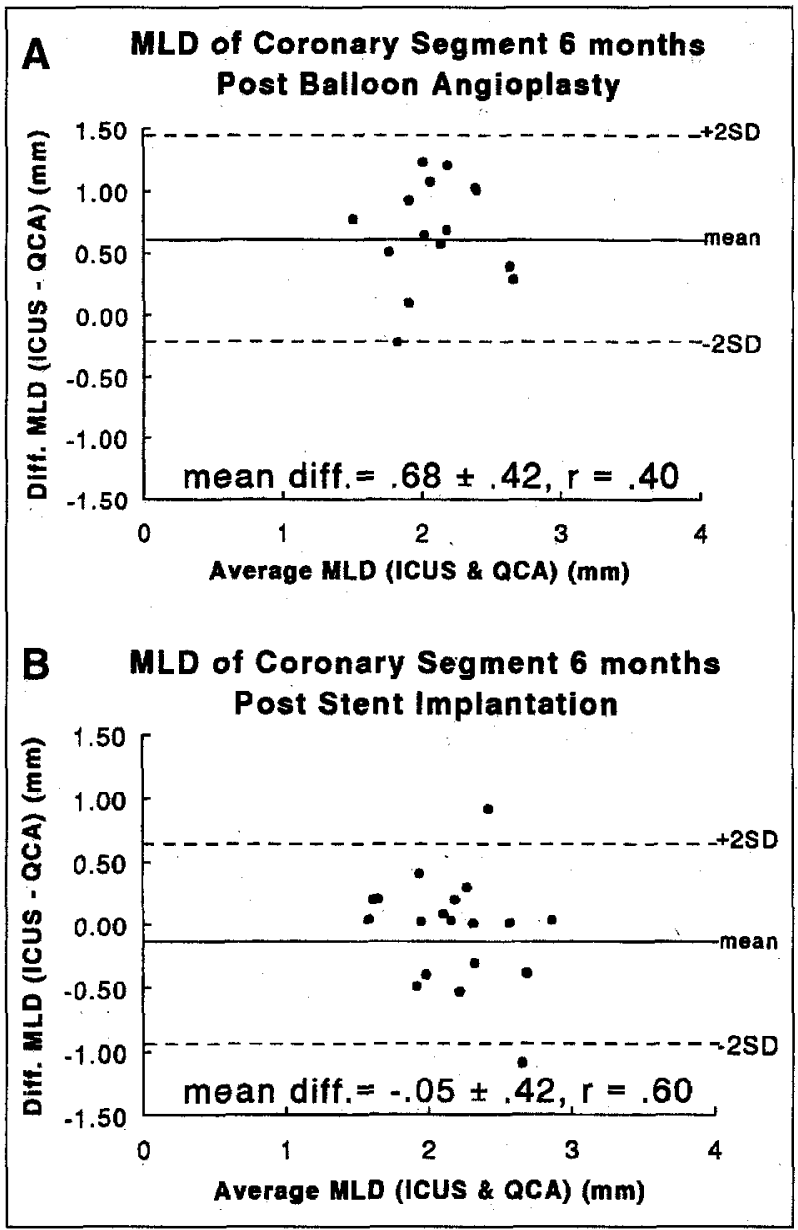

FIGURE 6. Agreement between measurements obtained from geomelric quantitative coronary angiographic analysis (QCA) and intracoronary ultrasound (ICUS) according to the statistical approach proposed by Bland and Alman ${ }^{20}$ at 6-month followup of patients who had undergone balloon angioplasty (A) and of patients who had undergone implantation of the radiopaque stent (B). A, the difference (diff.) in values between the ICUS and QCA measurements has been plotted against their mean value in 15 lesions without wedging of the ICUS catheter at follow-up in the balloon angioplasty group. $B$, the difference in values between the ICUS and QCA measurements has been plotted against their mean value in 20 lesions without wedging of the ICUS calheter at follow-up of patients who had undergone stent implantation. in close proximity to the border of the true lumen and may therefore interfere with the automated cdge detection, which may be unable to differentiate the outer contours of the lumen and stent struts. Second, the interpolated reference vessel diameter is based on multiple scanlines over a large extent of the analyzed segment, which will incorporate both scanlines that do and do not include the outer contour of the radiopaque stent struts.

Rather than using a subjective operator-selected reference point, the default mode of the CAAS system determines the size at the target coronary segment using an objective computer-derived interpolated reference diameter. $^{7-9,12-17}$ The interpolated reference diameter is derived from the edge-detected diameter function of the nonstenotic proximal and distal subsegments. The reference vessel diameter values are estimated by fitting a straight line to the diameter function proximal and distal to the obstruction, followed by a shift so that $80 \%$ of the diameter values are below the adjusted straight line. This line then represents the reconstructed reference diameter function and gives an estimate of the arterial size at each point along the analyzed coronary segment. The interpolated reference vessel diameter is taken as the value of the reconstructed diameter function at the position of the MLD. The advantages of this approach are that it is essentially user-independent and thus highly reproducible, and every measurement is based on multiple measurements (every scanline) proximal and distal to the lesion. The limitation of this technique is in ostial lesions where a proximal segment is unavailable and, in the case of this new highly radiopaque tantalum stent, where selection of a reference point either proximal or distal to the new Cordis tantalum stent (or an average of both) may prevent overestimation of vessel size associated with use of the default-interpolated reference vessel diameter mode.

Although not directly addressed by our study, it should be acknowledged that interference with the reliability of

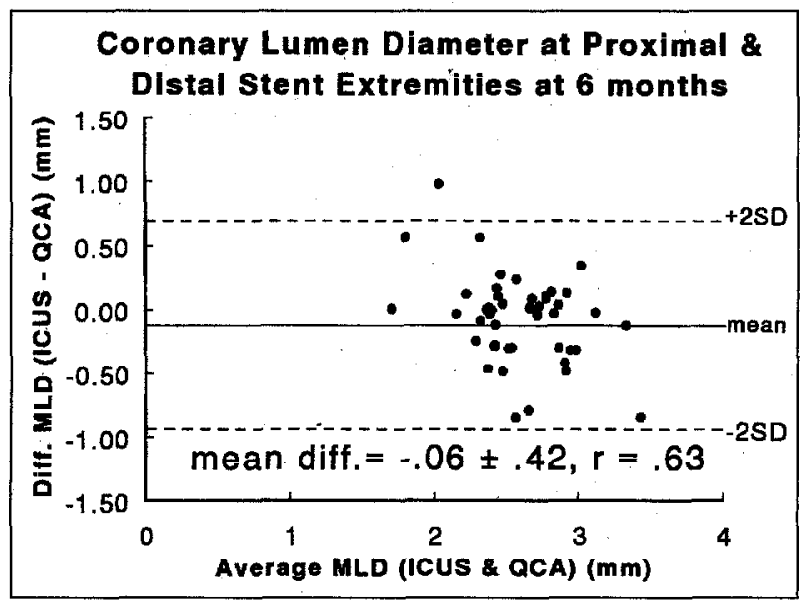

FIGURE 7. Agreement between measurements obtained from quantitative coronary angiographic analysis (QCA) and intracoronary ultrasound (ICUS) at the $\mathbf{4 6}$ proximal and distal extremities of the $\mathbf{2 3}$ stents at 6-month follow-up according to the statistical approach proposed by Bland and Alman. ${ }^{20}$ The differences (diff.) between intracoronary ultrasound and quantitative coronary angiographic analysis values have been plotted against their mean value. 
QCA by this new radiopaque stent may also occur immediately after stent implantation, and thus similar precautions in the application of QCA should be applied.

Limitations of intracoronary ultrasound: ICUS can provide clinically useful information on lesion and vessel characterization as well as on guidance of optimal stent deployment. ${ }^{27-30}$ However, the $2.9 \mathrm{Fr}$ size of the ultrasound catheter restricts application of ICUS for lumen quantification to lesions of $>1.0 \mathrm{~mm}$ in diameter because of mechanical wedging of the catheter. In our study, 3 of 23 stented lesions and 8 of the 23 lesions previously treated with balloon angioplasty showed signs of cathcter wedging, and these measurements were therefore excluded from analysis. Thus, although ICUS may be useful immediately after intervention for assessment of stent deployment, by 6-month follow-up lesions with significant restenosis may be unsuitable for ICUS evaluation. Furthermore, because the price of ultrasound catheters remains expensive (approximately $\$ 1,300$ ), it is difficult to justify the use of ICUS for routine followup of all stented patients.

Derivation of the MLD by ICUS measurement of the minimal luminal cross-sectional area $\left(\pi \mathrm{r}^{2}\right)$ inherently assumes a circular lumen, which may not be appropriate in the presence of severely eccentric atherosclerotic disease. Our use of a symmetric lumen in our phantom vessel allowed measurement by ICUS of the MLD to be obtained by either direct diameter measurement or by derivation from the minimal luminal cross-sectional area $\left(\pi r^{2}\right)$. The ratio of the 2 derived diameters in our stent and balloon angioplasty series was $0.89 \pm 0.08$ and 0.82 \pm 0.08 , respectively, consistent with a relatively symmetric lumen morphology at 6-month follow-up.

Given the unique inherent limitations of both ICUS and QCA techniques, the observation of a difference in their measurements in the absence of the known true diameter does not permit a conclusion on the absolute accuracy of either technique. We therefore included a phantom restenosis model with known internal dimensions to provide a measure of accuracy of both techniques.

Implications: For patients undergoing 6-month angiographic follow-up of this new radiopaque Cordis stent, measurements by QCA of the MLD may be performed reliably. When a QCA system is used that offers a default-interpolated reference vessel diameter mode, the reference vessel diameter of the stented segment may be overestimated and thus the severity of the percent diameter stenosis may also be overestimated, unless a manually selected reference point(s) proximal and/or distal to the Cordis tantalum stent is used. Alternatively, for determination of relative loss (absolute loss in MLD normalized for vessel size), the interpolated reference vessel diameter measured before intervention may be used.

At the time of stent implantation, and thus before the development of intimal hyperplasia, the stent struts will be in apposition to the vessel wall and thus the outer contour of the radiopaque stent struts should be coincident with the outer contour of the contrast-filled lumen. At this procedural phase, we do not find in clinical practice that the radiopacity of the stent struts interfere with on-line QCA during stent deployment. Thus, determination of the absolute (MLD post - MLD pre) and relative (MLD post - MLD pre normalized for reference vessel diameter pre) gain achieved at stent implantation, the absolute (MLD post - MLD follow-up) and relative (MLD post - MLD follow-up normalized for reference vessel diameter pre) loss in MLD over 6 months, and the loss index (loss/gain) (restenosis process), as well as measurement of the absolute MLD at follow-up (final outcome), should be feasible with QCA in patients undergoing implantation of this tantalum stent.

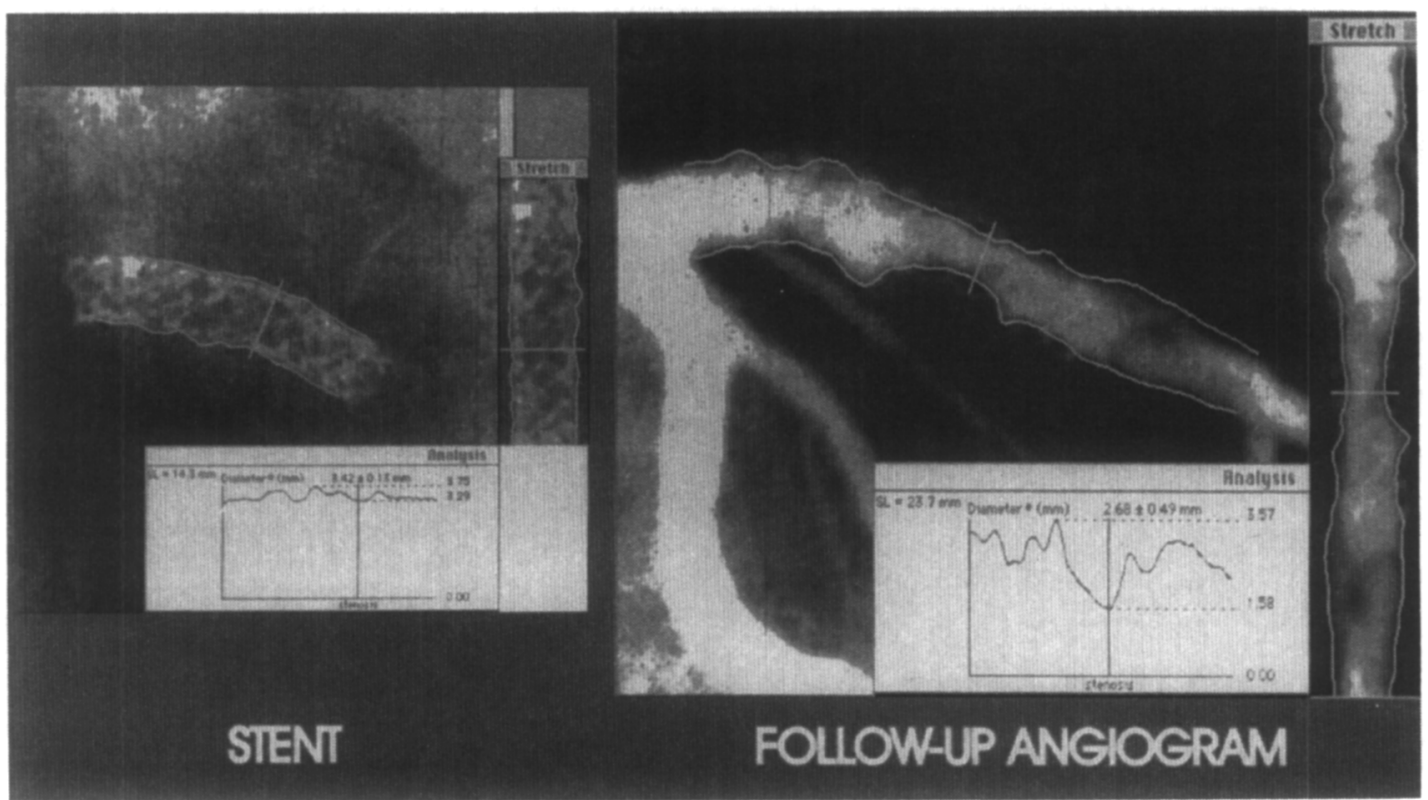

FIGURE 8. At 6-month follow-up angiography, the radiopacity of the new Cordis tantalum stent can be traced by automated edge detection without contrast media (left panel). In this patient, automated edge detection of the minimal luminal diameter appeared to function reliably after contrast injection (right panel). 
Acknowledgment: We gratefully acknowledge the dedication and radiographic advice of Ad den Boer, MSc, and the assistance of Eline Montauban van Swijndregt, $\mathrm{MSc}$, in the preparation of the figures.

1. Schatz RA, Baim DS, Lcon M, Ellis SG, Goldberg S, Hirshfeld JW, Clemen MW, Cabin HS, Walker C, Stagg J, Buchbinder M, Tierstein PS, Topol EJ, Savage M, Perez JA, Curry RC, Whitworth H, Sousa JE, Tio F, Almagor Y, Ponder R, Penn IM, Leonard B, Levine SL, Fish RD, Palmaz JC. Clinical experience with the Palmaz-Schatz coronary stent: initial results of a multicenter study. Circulation 1991;83:148-161.

2. Roubin GS, Cannon AD, Agrawal SK, Macander PJ, Dean LS, Baxley WA, Breland $\mathbf{J}$. Intracoronary stenting for acute and threatened closure complicating percutaneous transluminal coronary angioplasty. Circulation 1992;85:916-927.

3. Sigwart U, Puel J, Mircowitch V, Joffre F, Kappenberger L. Intravascular stents to prevent occlusion and restenosis after transluminal angioplasty. $N$ Engl $J$ Med. 1987;316:701-706.

4. Ozaki Y, Keane D, Ruykrok P, de Feyter PJ, Stertzer S, Serruys PW. Acute clinical and angiographic results with the new AVE micro coronary stent in bailout management. Am J Cardiol 1995;76:112-116.

5. Strauss BH, Rensing BJ, den Boer A, van der Giessen WJ, Reiber JHC, Sernys PW. Do stents interfere with the densitometric assessment of a coronary artery lesion? Cathel Cardiovasc Diagn 1991;24:259-264.

6. deJaegere PP, Serruys PW, Bertrand M, Wiegand V, Kober G, Marquis JF, Valeix B, Uebis R, Piessens J. Wiktor stent implantation in patients with restenosis following balloon angioplasty of a native coronary artery. Am J Cardiol 1992;69:598-602. 7. Haase J, Escaned J, Swijndregt EM, Ozaki Y, Gronenschild ED, Slager CJ, Serruys PW. Experimental validation of geometric and densitometric coronary measurements on the new generation cardiovascular angiography analysis system (CAAS II). Cathet Cardiovasc Diagn 1993;30:104-114

B. Ozaki Y, Keane D, Herrman JP, Foley D, Haase J, den Boer AD, Di Mario C, Serruys PW. Coronary arteriography for quantitative analysis: an experimental and clinical comparison of cinefilm and video recordings. Am Heart $J$ 1995;129:471-475. 9. Keane D, Haase J, Slager CJ, van Swijndregt EM, Lehmann K, Ozaki Y, Di Mario C, Kirkeedee R, Serruys PW. Comparative validation of quantitative coronary angiographic systems. Results and implications from a multicenter study. Circulation 1995;91:2174-2183.

10. Wollschlager H, Lee P, Zeiher A, Solzbach U, Bonzel T, Just H. Improvement of quantitative angiography by exact calculation of radiological magnification factors. Comp Cardiol 1985;483-486.

11. Lablanche JM, Leroy F, McFadden EP, Bauter C, Bertrand ME. Dose-response curve of angiographically smooth human epicardial vessel segments to intracoronary injections of isosorhide dinitrate. I Cardiovasc Pharmacol 1992;20:473-478. 12. Ozaki Y, Keane D, Serruys PW. Relationship of basal coronary tone and vasospastic activity in patients with variant angina: a quantitative angiographic study. Br Heart $J$ 1996; in press.

13. Serruys PW, Booman F, Troost GJ, Reiber JHC, Gerbrands JJ, van den Brand M, Cherrier F, Hugenholtz PG. Computerized quantitative coronary angiography applied to percutaneous transluminal coronary angioplasty: advantages and limitations. In: Kaltenbach M, Gruntzig $\Lambda$, Rentrop K, Bussmann WD, eds. Transluminal Coronary Angiography and Intracoronary Thrombolysis. Coronary Heart Disease IV. Berlin: Springer-Verlag, 1982:110-124.

14. Reiber JHC, Serruys PW, Kooijman CJ, Wijns W, Slager CJ, Gerbrands JJ, Schuurbiers JHC, Den Boer A, Hugenholtz PG. Assessment of short-, medium-, and long-term variations in arterial dimensions from computer-assisted quantitation of coronary cineangiograms. Circulation 1985:71:280-288.

15. Serruys PW, Luyten HE, Beatt KJ, Geuskens R, de Feyter PJ, Brand M, Reiber JHC, Katen HJ, Es GA, Hugenholtz PG. Incidence of restenosis after successful coronary angioplasty: a time-related phenomenon; a quantitative angiographic study in 342 consecutive patients at 1, 2, 3, and 4 months. Circulation 1988;77:361-371. 16. Gronenschild E, Janssen J, Tijdens F. CAAS II: a second generation system for off-line and on-line quantitative coronary angiography. Cathet Cardiovasc Diagn 1994;33:61-75.

17. Ozaki Y, Keane D, Serruys PW. Progression and regression of coronary stenosis in the long-term follow-up of vasospastic angina: a quantitative angiographic study. Circulation 1995; in press.

18. Herrmann JP, Keane D, Ozaki Y, den Boer A, Serruys PW. Radiological quality of coronary guiding catheters: a quantitative analysis. Cathet Cardiovasc Diagn 1994:33:55-60.

19. Keane D, Serruys PW. Quantitative coronary angiography: an integral compo nent of interventional cardiology. In: Topol EJ, Serruys PW, eds. Current Review of Interventional Cardiology. 2nd ed. Philadelphia: Current Medicine, 1995:205-233. 20. Bland JM, Altman DG. Statistical methods for assessing agreement between two methods of clinical measurement. Lancet 1986;2:307-310.

21. Nissen SE, Gurley JC, Grines CL, Booth DC, McClure R, Berk M, Fisher C, DeMaria AN. Intravascular ultrasound assessment of lumen size and wall morphology in normal subjects and patients with coronary artery disease. Circulation 1991;84:1087-1099.

22. St. Goar FG, Pinto FJ, Alderman EL, Fitzgerald PJ, Stinson EB, Billingham ME, Popp RL. Detection of coronary atherosclerosis in young adult hearts using intravascular ultrasound. Circulation 1992;86:756-763.

23. Tobis JM, Mallery J, Mahon D, Lehmann K, Zalesky P, Griffith J, Gessert J, Moriuchi M, McRae M, Dwyer ML, Greep N, Henry WL. Intravascular ultrasound imaging of human coronary arteries in vivo - analysis of tissue characterization with comparison to in vitro histological specimens. Circulation 1991;83:913-926. 24. DeScheerder I, de Man F, Herregods MC, Wilczek K, Barrios L, Raymenants E, Desmet W, de Geest H, Piessens J. Intravascular ultrasound versus angiography for measurement of luminal diameters in normal and diseased coronary arteries. Am Heart $J$ 1994;127:243-251.

25. Haase J, Ozaki Y, Di Marin C, Escaned I, de Feyter P, Rnelandt JRTC., Serruys PW. Can intracoronary ultrasound correctly assess the luminal dimensions of coronary artery lesions? A comparison with quantitative angiography. Eur Heart $\mathrm{J}$ 1995;16:112-119.

26. Ozaki Y, Keane D, Di Mario C, Baptista J, Haase J, Roelandt JRTC, Serruys PW. Comparison of coronary luminal area obtained from intracoronary ultrasound quantitative coronary angiography (QCA; edge-detection algorithm and videodensitometry) after successful PTCA and DCA (abstr). J Am Coll Cardiol 1994;23(supp1):70A.

27. Nakamura S, Colombo A, Gaglione S, Almagor Y, Goldberg SL, Maiello L Finci L, Tobis JM. Intracoronary ultrasound observations during stent implantation. Circulation 1994;89:2026-2034.

28. Colombo A, Hall P, Nakamura S, Almagor Y, Maiello L, Martini G, Gaglione A, Goldberg SL, Tobis JM: Intracoronary stenting without anticoagulation accomplished with intravascular ultrasound guidance. Circulation 1995;91:1676-1688. 29. Mintz GS, Popma JJ, Pichard A, Kent KM, Satler LF, Wong SC, Kleiber B, Painter JA, Kehoe MK, Leon MB. Mechanism of balloon angioplasty of in-stent restenosis: an intravascular ultrasound study (abstr). J Am Coll Cardiol 1995;25(suppl):197A.

30. Di Mario C, Keane D, Serruys PW. Sizing of stents: quantitative coronary angiography or intravascular ultrasound? In: Sigwart U, ed. Endovascular Stents. London: Saunders \& Co., 1996; in press. 